\title{
On the sub-decadal variability of South Atlantic Antarctic Intermediate Water
}

\author{
G. D. McCarthy, ${ }^{1}$ B. A. King, ${ }^{1}$ P. Cipollini, ${ }^{1}$ E. L. McDonagh, ${ }^{1}$ J. R. Blundell, ${ }^{1}$ \\ and A. Biastoch ${ }^{2}$
}

Received 9 February 2012; revised 3 April 2012; accepted 7 April 2012; published 22 May 2012.

[1] Variability of Antarctic Intermediate Water salinity in the South Atlantic is investigated on interannual and intradecadal timescales. Novel observations of slow, westward propagating salinity anomalies in Argo data are presented. The features have no corresponding signal in temperature and are anomalous in density. Analysis of 40 years of model output supports the existence of these westward propagating salinity anomalies and indicates that they are typical occurrences in time. The features are intensified in a latitude band around $30^{\circ} \mathrm{S}$ associated with the propagation of Agulhas rings. However, the features are much larger than Agulhas rings and occur on decadal timescales in the model. They propagate westward with speeds of $2.3 \mathrm{~cm} / \mathrm{s}$ in observations, and $1.7 \mathrm{~cm} / \mathrm{s}$ in model data. They are more consistent with planetary waves than with the advection of large-scale salinity anomalies. The observation of these features has implications for the interpretation of salinity anomalies, such as the linking of hydrological cycle changes to salinity changes. Citation: McCarthy, G. D., B. A. King, P. Cipollini, E. L. McDonagh, J. R. Blundell, and A. Biastoch (2012), On the subdecadal variability of South Atlantic Antarctic Intermediate Water, Geophys. Res. Lett., 39, L10605, doi:10.1029/2012GL051270.

\section{Introduction}

[2] Antarctic Intermediate Water (AAIW) is a water mass present throughout the southern hemisphere oceans of the world [Talley, 1996], identifiable by a salinity minimum in vertical profiles in the southern Atlantic (Figures 1a and 1b), Pacific and Indian oceans. It is a water mass that forms part of the upper branch of the Atlantic Meridional Overturning Circulation (AMOC) and can be identified in the North Atlantic, having been transported from the Southern Ocean as part of the AMOC.

[3] The salinity of AAIW is of particular interest in analysis of the impacts of a changing hydrological cycle. The hydrological cycle is expected to intensify in a changing climate [Bindoff et al., 2007]. As a consequence, AAIW is expected to decrease in salinity. This is because AAIW either outcrops in the Southeast Pacific [McCartney, 1977;

\footnotetext{
${ }^{1}$ National Oceanography Centre, Southampton, UK.

${ }^{2}$ Ocean Circulation and Climate Dynamics, GEOMAR, Helmholtz Centre for Ocean Research Kiel, Kiel, Germany.

Corresponding author: G. D. McCarthy, National Oceanography Centre, European Way, Southampton SO14 3ZH, UK. (gerard.mccarthy@noc.ac.uk)

Copyright 2012 by the American Geophysical Union. 0094-8276/12/2012GL051270
}

Talley, 1996] or in the Bellinghausen Sea [Santoso and England, 2004; Naveira-Garabato et al., 2009] - both regions where precipitation dominates over evaporation.

[4] Freshening of AAIW has been observed in the Pacific [Wong et al., 1999] and the Indian Oceans [Bindoff and McDougall, 2000; Bryden et al., 2003; McDonagh et al., 2005]. However, in the South Atlantic the situation is not as clear cut. A unique aspect of South Atlantic AAIW circulation is the influence of the Agulhas region and Indian Ocean inflow into the South Atlantic basin which brings warm, salty thermocline water from the Indian Ocean via Agulhas rings [e.g., de Ruijter et al., 1999] and has a strong dynamic influence on the South Atlantic [Beal et al., 2011; Biastoch et al., 2008].

[5] In the South Atlantic, Curry et al. [2003] found that AAIW salinity had decreased on isopycnals from the 1950s/ 1960s to the 1980s/1990s but both Arbic and Owens [2001] and McCarthy et al. [2011] noted an increase in AAIW salinity at $24^{\circ} \mathrm{S}$ from 1958 to 1983 . McCarthy et al. [2011] linked the changes in AAIW salinity to changes in circulation rather than changes in the hydrological cycle. Warming of AAIW has also been noted throughout the southern hemisphere in Argo data [Schmidtko and Johnson, 2012] and hydrographic data [Arbic and Owens, 2001; McCarthy et al., 2011]. Little is known about how AAIW varies on intradecadal and interannual timescales, and higher frequency variability could well be the cause for disagreement between studies.

[6] This paper uses Argo data and model output to investigate changes in salinity and temperature on the salinity minimum of AAIW in the South Atlantic. Novel observations of AAIW in Argo data show that large, westward propagating, salinity anomalies exist in the South Atlantic. Analysis of 40 years of model output supports the existence of these westward propagating salinity anomalies and indicates that they are typical occurrences in time. There is no corresponding feature in temperature. These features are analysed and discussed, with hypotheses on the possible implications of their discovery.

\section{Propagating Salinity Features in Argo Data}

[7] Variations in AAIW were investigated by analysing properties on the salinity minimum of AAIW (Figure 1b). Analysis of AAIW on the independent salinity minimum has the advantage over analysis in density classes that salinity and temperature changes are distinct from one another. A data set was extracted from a combination of quality controlled and high quality real-time Argo float profiles. A total of 79000 float profiles were used in this study from throughout the South Atlantic, though the latitude of $30^{\circ} \mathrm{S}$ 

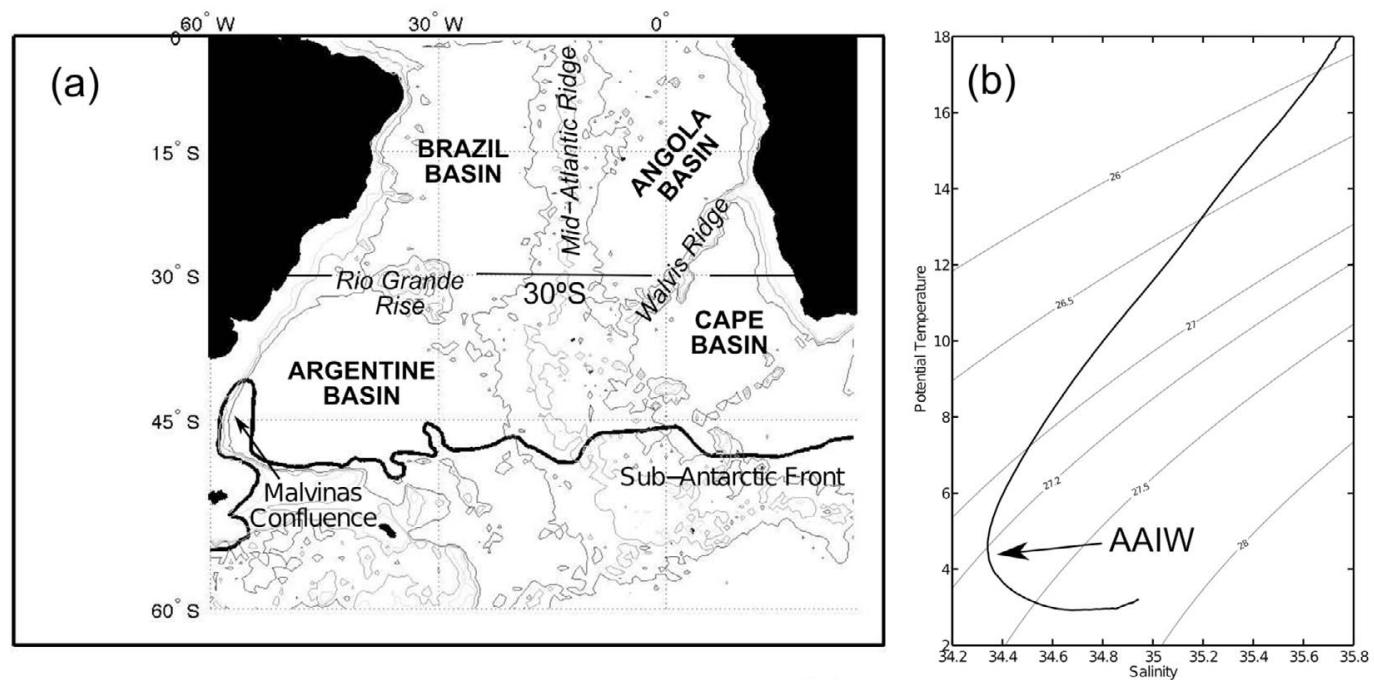

(c)

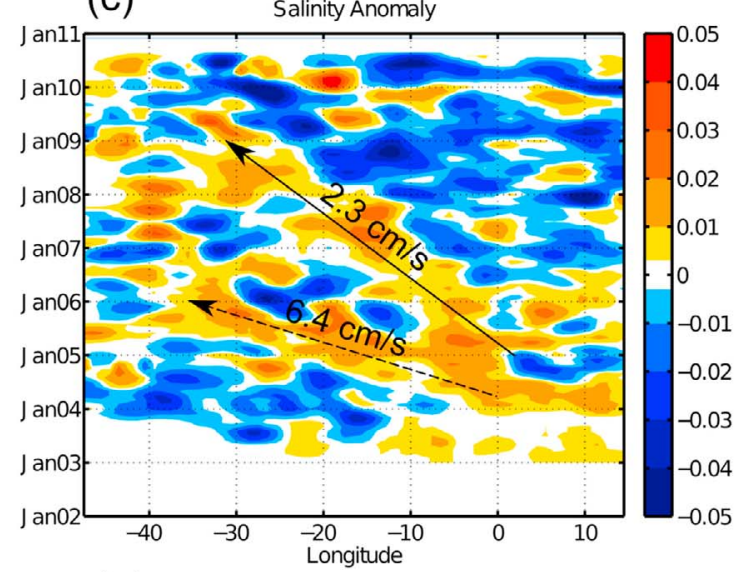

(e)
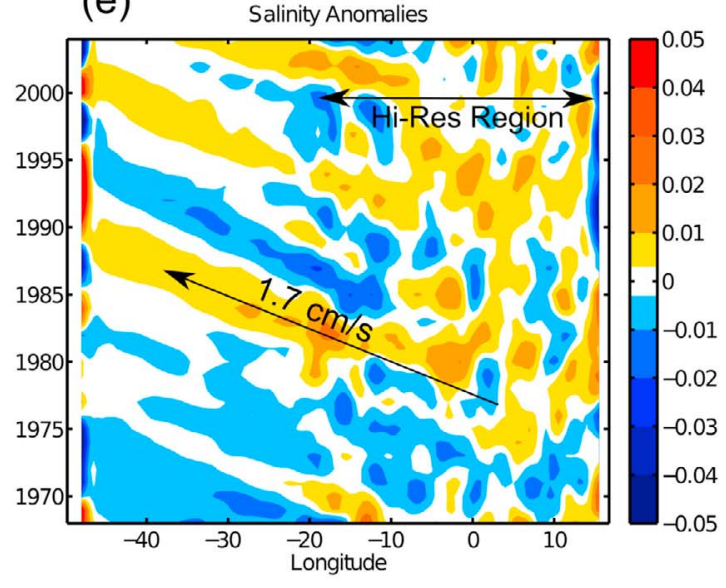

(d)

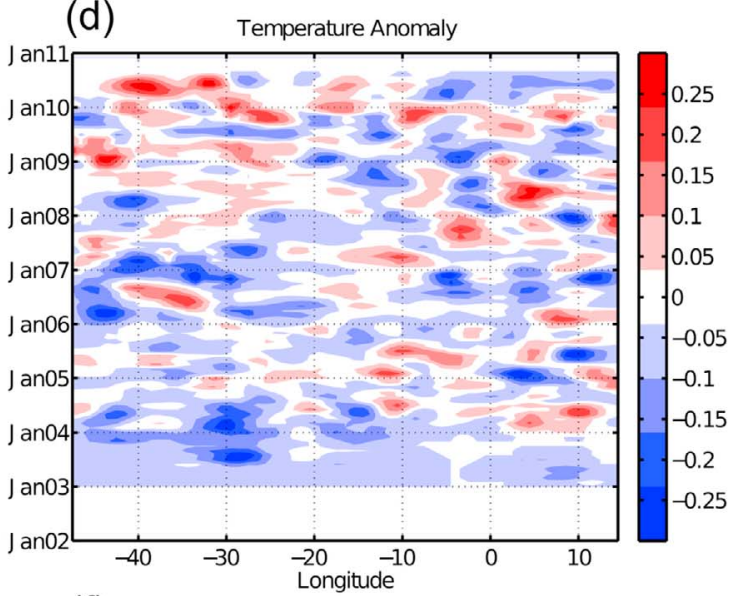

(f)

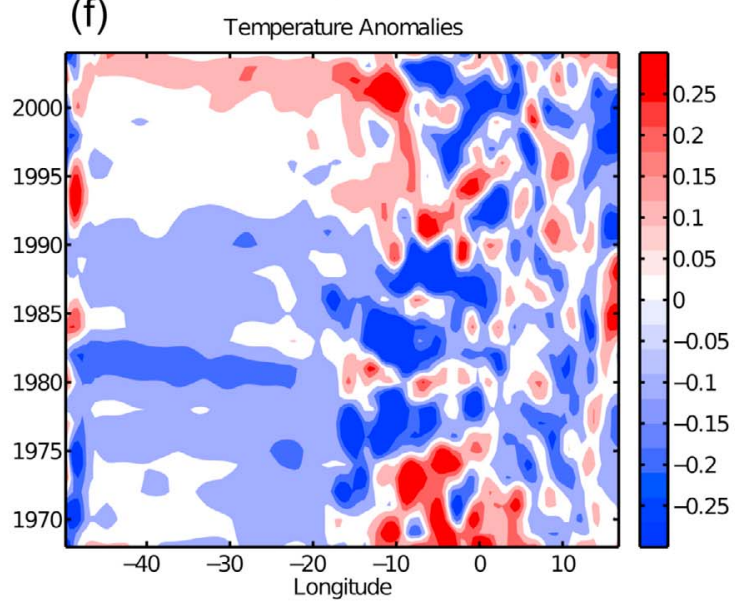

Figure 1. (a) The South Atlantic with major topographic features highlighted. (b) The mean $\theta-\mathrm{S}$ relationship in the top $2000 \mathrm{~m}$ of the South Atlantic from Argo data with the salinity minimum of AAIW highlighted. Optimally interpolated Argo (c) salinity and (d) temperature anomalies in South Atlantic AAIW at $30^{\circ} \mathrm{S}$ from 2003 to 2011. The major salinity anomaly propagates westward from $0^{\circ} \mathrm{E}$ at the start of 2004 with a speed of $2.3 \mathrm{~cm} / \mathrm{s}$. A secondary salinity anomaly with a speed of $6.4 \mathrm{~cm} / \mathrm{s}$ is indicated with a dashed line. There is no similar signal in temperature. Colour bars are chosen such that the range of colour in salinity and temperature anomaly has a similar impact on density. (e) Salinity and (f) temperature anomalies from model output in South Atlantic AAIW at 30 ${ }^{\circ} \mathrm{S}$ from 1968 to 2004. Temperature fields show basinwide slow changes in temperature. Again color bars are chosen such that changes in salinity and temperature of similar colour change are density compensating. 


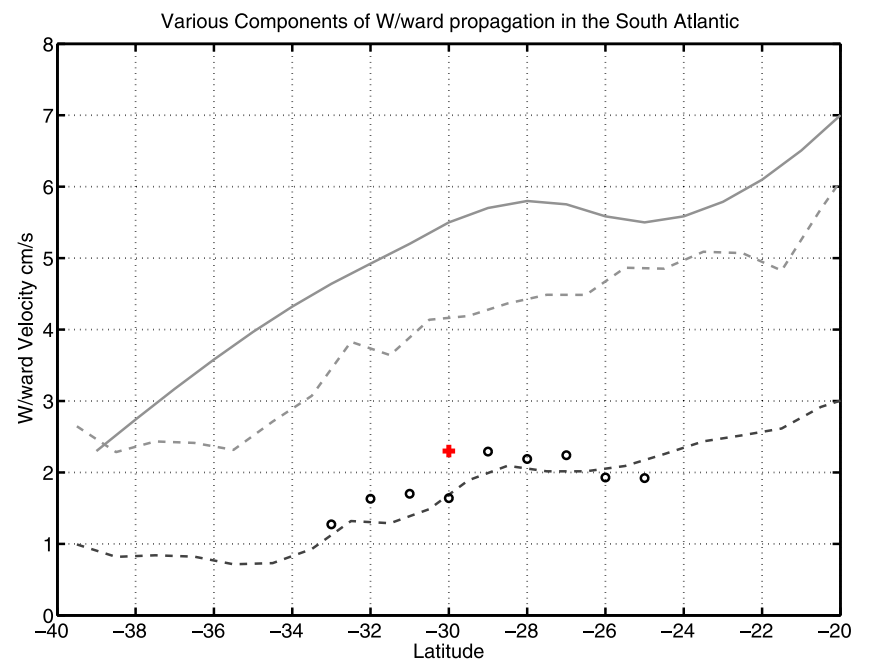

Figure 2. A summary of modes of propagation in the subtropical South Atlantic. The speeds of the propagating features observed in the South Atlantic AAIW salinity are shown with black open circles, in the case of model output, and a red cross, in the case of Argo data. The solid light grey line is an average of the speeds of propagation observed in SSHA by Polito and Liu [2003]. A theoretical estimate of the first mode (light grey dashed line) and second mode (dark grey dashed line) baroclinic Rossby wave speed from Killworth and Blundell [2003a, 2003b] is included.

had the highest data density. Vertical profiles of temperature and salinity were fitted to a regular pressure grid using an Akima spline [Akima, 1970], before extraction of the data corresponding to the salinity minimum. This technique has been shown to reduce errors in estimating the salinity at the salinity minimum due to lack of vertical resolution to the order of 0.001 in salinity [McCarthy, 2011]. Monthly temperature and salinity data were optimally interpolated onto a regular longitude-time grid, using a decay scale of $300 \mathrm{~km}$ [McCarthy, 2011]. The use of this spatial scale has the impact of smoothing out the effect of individual eddies. This is particularly important in this location where Agulhas rings - with a typical radius of $120 \mathrm{~km}$ [de Ruijter et al., 1999] are prevalent. Zero-mean, longitude-time anomaly fields were constructed by subtracting longitude and time averages of the data. The final anomaly fields were then three month boxcar filtered to remove higher frequency variability. The final longitude-time plots of salinity and temperature anomalies at $30^{\circ} \mathrm{S}$ are shown in Figures 1c and $1 \mathrm{~d}$. The colour bars are chosen such that the colour ranges for salinity and temperature anomalies would have the same effect on density.

[8] Westward propagating salinity anomalies stand out in Figure 1c, propagating westwards from January 2004. There is a significant change in salinity of up to 0.06 peak to trough. This is large considering that a basinwide change of only 0.03 was observed between 1958 and 1983 at $24^{\circ} \mathrm{S}$ [McCarthy et al., 2011] and a change of 0.01 was observed between 1993 and 2003 at $30^{\circ} \mathrm{S}$ [McCarthy, 2011]. The anomaly is not density compensating as there is no corresponding feature in temperature (Figure 1d).

[9] Both fields were analysed using the 2-dimensional Radon transform [Challenor et al., 2001]. The Radon transform informs of the speed of propagation of wavelike features and is more suitable than a Fourier Transform for analysis of individual features. The major peak in the Radon transform corresponds to the salinity anomaly with a speed of $2.3 \mathrm{~cm} / \mathrm{s}$ (solid line, Figure 1c). A secondary peak in the Radon transform indicates a salinity anomaly propagating with a speed of $6.4 \mathrm{~cm} / \mathrm{s}$ (dashed line, Figure 1c). No significant peaks of propagation were identified in the temperature anomaly field.

\section{Presence in Model Output}

[10] The realistically forced model (AG01-R) is a high resolution $\left(1 / 10^{\circ}\right)$ model of the greater Agulhas region nested into a global ocean/sea-ice model of $1 / 2^{\circ}$ resolution [Biastoch et al., 2008], which has been shown to represent the region well, resolving the mesoscale features, which are important in the region. The model has 46 vertical levels. At the depth of the AAIW minimum the vertical grid has a resolution of around $100 \mathrm{~m}$ which is sufficient to resolve the spreading of AAIW. This model is examined relative to a sensitivity model run (AG01-C), which is driven by repeated year forcing so it explicitly excludes any inter-annual or anthropogenic forcing trend. Examining the AG01-R output relative to the AG01-C output acts to remove model drift. The high resolution nest covers the region $7^{\circ} \mathrm{S}$ to $47^{\circ} \mathrm{S}$ and $20^{\circ} \mathrm{W}$ to $20^{\circ} \mathrm{E}$.

[11] Temperature and salinity values are extracted from both model outputs corresponding to the salinity minimum of AAIW. Salinity and temperature anomalies were calculated from AG01-R with AG01-C values subtracted. From here, the model output is treated similarly to the Argo data. Zero-mean longitude-time plots of these anomalies were created by subtracting means in both longitude and time. The anomalies were then filtered using a $1.5^{\circ}$ longitude and 24 month boxcar filter. While the features described below are robust in the unfiltered output, the 24 month filter is used to explicitly exclude sub-annual variability, which especially affects the high resolution region. Figures $1 \mathrm{e}$ and $1 \mathrm{f}$ show the salinity and temperature anomaly at $30^{\circ} \mathrm{S}$ for the full model run from 1968 to 2004 . The high resolution nest is indicated in the higher variability east of $20^{\circ} \mathrm{W}$.

[12] Westward propagating salinity anomalies are visible throughout the model run from 1968 to 2004. Similar features are not present in the temperature data. This is consistent with the observation in the shorter time period of Argo data. The existence of multiple propagating salinity features in the model output suggest that, as the timespan of Argo is extended, more of these features should emerge.

[13] This result indicates that westward propagating salinity anomalies are a robust feature in the South Atlantic and that the anomalies are not density compensating. Analysis with a Radon transform yields a propagation speed of $1.7 \mathrm{~cm} / \mathrm{s}$ causing decadal salinity oscillations of up to 0.06 peak to trough, similar to Argo data. No other propagation speed emerges from the Radon transform analysis.

[14] The changes in temperature (Figure 1f) do not show a predominance of slow, westward propagating anomalies. Basinwide changes - generally from cold to warm - are evident.

[15] Speeds of propagation from the model at different latitudes are shown in Figure 2: south of $33^{\circ} \mathrm{S}$ and north of $25^{\circ} \mathrm{S}$ no coherent speed of propagation is discernable. The 
westward propagating salinity signals are most intense around $28^{\circ} \mathrm{S}$ and $30^{\circ} \mathrm{S}$ and lose intensity away from these latitudes.

[16] Investigations of salinity anomalies on potential temperature surfaces in the thermocline did not show a dominance of westward propagating anomalies. Rather, over the model run, large basinwide oscillations in salinity masked any propagating features. Basinwide changes in salinity are similar to those observed by McCarthy et al. [2011].

\section{Analysis of Westward Propagating Salinity Features}

[17] The analysis shows that westward propagating salinity signals are the dominant form of variability in AAIW salinity on interannual timescales observed in Argo data and are also the most visible features over the four decades of the model run. Figure 1e shows an anomaly field reminiscent of the westward propagating sea-surface height [Polito and Liu, 2003], which display a first baroclinic mode Rossby wave signature. The salinity anomalies in Figure 1e do not propagate with the speeds associated with first mode baroclinic Rossby waves observed in satellite data, which would travel at around $5 \mathrm{~cm} / \mathrm{s}$ at this latitude [Polito and Liu, 2003]. These features are much slower with speeds of $1.7 \mathrm{~cm} / \mathrm{s}$.

[18] The speeds of propagation of the salinity anomalies in the model are compared with predicted speeds of first and second baroclinic modes from Killworth and Blundell [2003a, 2003b] in Figure 2. Speeds of westward propagation of SSH anomalies from Polito and Liu [2003] are also shown. The speeds derived from the model agree broadly with those predicted for second mode, baroclinic Rossby waves.

[19] The model salinity anomalies have their highest speeds between $30^{\circ} \mathrm{S}$ and $29^{\circ} \mathrm{S}$. This is a similar latitude band to an enhanced westward propagation of SSH anomalies [Polito and Liu, 2003] and is a band of latitude preferred for the propagation of Agulhas rings [Chelton et al., 2011].

\section{Discussion}

[20] In both Argo data and model data it is clear that, at AAIW depths, salinity features which propagate across the basin are the dominant mode of variability. This is the case, not only on interannual timescales as shown by Argo data, but also on decadal timescales, as shown by model data. They propagate with speeds between $2.3 \mathrm{~cm} / \mathrm{s}$ (Argo data) and $1.7 \mathrm{~cm} / \mathrm{s}$ (Model data), which are close to the speed of second mode baroclinic Rossby waves [Killworth and Blundell, 2003a, 2003b]. The features are strongest in a latitude band around $28^{\circ} \mathrm{S}$ to $30^{\circ} \mathrm{S}$, which is associated with the propagation of Agulhas rings across the basin indicating a likely link with the Indian Ocean.

[21] These novel observations raise three major questions: what are these features, what causes them and what are the implications of their observation?

[22] The features propagate westward with a speed close to those predicted for second mode baroclinic Rossby waves. They occur once or twice a decade and have wavelengths of the order of $1000 \mathrm{~km}$ (Figure 1e). This scale is much larger than the familiar eddies associated with the first baroclinic mode of propagation [Chelton et al., 2011]. In particular given this region, the features are not Agulhas rings. Agulhas rings are anti-cyclonic eddies with a mean diameter of $240 \mathrm{~km}$ shed on average six times per year from the Agulhas retroflection [de Ruijter et al., 1999]. The features observed here are much bigger and slower.

[23] The features are not consistent with simple advection of salinity anomalies across the basin. If advection was the cause of these features, they would propagate in a manner similar to the circulation of AAIW. Hence eastward propagating features would be seen around $40^{\circ} \mathrm{S}$ in the South Atlantic Current and the major channel for westward propagation would be $25^{\circ} \mathrm{S}$ in the extended Benguela Current [Stramma and England, 1999]. What is seen is westward propagation focused in the latitudes around $28^{\circ} \mathrm{S}$ to $30^{\circ} \mathrm{S}$, which is the centre of the subtropical gyre in the South Atlantic and not associated with any zonal currents.

[24] The features could be caused by decadal oscillations in the amount of water transferred between the Indian and Atlantic oceans. Agulhas rings bring in warm, salty thermocline and intermediate water [de Ruijter et al., 1999] to the South Atlantic from the Indian Ocean. Lagrangian tracking of particles in the model indicate that $60 \%$ of the AAIW in the Atlantic originates in the Indian Ocean. However, analysis of the leakage between the oceans did not show decadal oscillations similar to the oscillations seen in salinity.

[25] These features are more likely due to a dynamical signal being transferred between the ocean basins. Dynamical signals from the Agulhas region have, on decadal timescales, been seen in this model [Biastoch et al., 2008]. If these dynamical signals are the westward propagating features seen and acted to speed/slow the gyre, it would affect the rate at which AAIW is circulated.

[26] AAIW is a salinity minimum; as it ages, it mixes with more saline water around it. The rate of change of salinity of AAIW has been estimated at 0.01 per year [McCarthy, 2011]. If the gyre slows then AAIW salinity increases and this will be evident in the salinity being transmitted across the basins in these propagating features.

[27] Further work is needed to prove the link between the circulation of AAIW and its salinity. For example, Biastoch et al. [2009] showed that over the run of this model the gyre spun up, which should lead to a reduction in AAIW salinity. On the other hand, Agulhas leakage also increased, which should lead to an increase in AAIW salinity. Neither trend was noted in AAIW salinity here so the relationship between AAIW salinity and gyre circulation is not obvious.

[28] The observation of these subsurface propagating salinity features is novel and is likely to take some time to fully explain. However, an immediate consequence is on the interpretation of salinity changes of AAIW in terms of the hydrological cycle. This paper has demonstrated that AAIW salinity variability on subdecadal timescales is dominated by large, slow, westward propagating anomalies. Traditional analysis of properties on hydrographic sections cannot account for the salinity variability caused by these features [e.g., Arbic and Owens, 2001; Curry et al., 2003; McCarthy et al., 2011] and this 0.06 magnitude salinity anomaly is such that it is large compared to changes reported in these studies at AAIW depth. At shallower depths, large salinity anomalies occur intermittently [e.g., McCarthy et al., 2011] and are usually associated with eddies. However, this magnitude salinity anomaly in AAIW is quite significant. These features are consistent with dynamical signals in the gyre 
and not decadal changes in water mass properties. Thus any analysis of AAIW salinity changes needs to account for this dynamic variation when interpreting salinity changes in terms of hydrological forcing.

[29] Acknowledgments. GM was supported by the Marine Physics and Ocean Climate group and the University of Southampton. The Argo data were collected and made freely available by the International Argo Program and the national programs that contribute to it. (http://www.argo. ucsd.edu, http://argo.jcommops.org). The Argo Program is part of the Global Ocean Observing System.

[30] The Editor thanks two anonymous reviewers for their assistance in evaluating this paper.

\section{References}

Akima, H. (1970), A new method of interpolation and smooth curve fitting based on local procedures, J. Comput. Math., 17, 589-602.

Arbic, B. K., and W. B. Owens (2001), Climatic warming of Atlantic Intermediate Waters, J. Clim., 14, 4091-4108.

Beal, L. M., et al. (2011), On the role of the Agulhas system in ocean circulation and climate, Nature, 472, 429-436.

Biastoch, A., C. W. Boning, and J. R. E. Lutjeharms (2008), Agulhas leakage dynamics affects decadal variability in Atlantic overturning circulation, Nature, 456, 489-492.

Biastoch, A., C. W. Boning, F. U. Schwarzkopf, and J. R. E. Lutjeharms (2009), Increase in Agulhas leakage due to poleward shift of Southern Hemisphere westerlies, Nature, 462, 495-499.

Bindoff, N. L., and T. J. McDougall (2000), Decadel changes along an Indian Ocean section at $32^{\circ} \mathrm{S}$ and their interpretation, J. Phys. Oceanogr., $30,1207-1222$

Bindoff, N. L., et al. (2007), Observations: Oceanic climate change and sea level, in Climate Change 2007: The Physical Science Basis. Contribution of Working Group I to the Fourth Assessment Report of the Intergovernmental Panel on Climate Change, edited by S. Solomon et al., pp. 355-432, Cambridge Univ. Press, Cambridge, U. K.

Bryden, H. L., E. L. McDonagh, and B. A. King (2003), Changes in ocean water mass properties: Oscillations or trends?, Science, 300, 2086-2088.

Challenor, P. G., P. Cipollini, and D. Cromwell (2001), Use of the 3D radon transform to examine the properties of oceanic Rossby waves, J. Atmos. Oceanic Technol., 18, 1558-1566.

Chelton, D. B., M. G. Schlax, and R. M. Samelson (2011), Global observations of nonlinear mesoscale eddies, Progr. Oceanogr., 91, 167-216.

Curry, R., B. Dickson, and I. Yashayaev (2003), A change in the freshwater balance of the Atlantic Ocean over the past four decades, Nature, 426 , $826-829$. de Ruijter, W. P. M., A. Biastoch, S. S. Drijfhout, J. R. E. Lutjeharms, R. P. Matano, T. Pichevin, P. J. van Leeuwen, and W. Weijer (1999), Indian-Atlantic interocean exchange: Dynamics, estimation and impact, J. Geophys. Res., 104(C9), 20,885-20,910.

Killworth, P. D., and J. R. Blundell (2003a), Long extratropical planetary wave propagation in the presence of slowly varying mean flow and bottom topography. Part I: The local problem, J. Phys. Oceanogr., 33, $784-801$

Killworth, P. D., and J. R. Blundell (2003b), Long extratropical planetary wave propagation in the presence of slowly varying mean flow and bottom topography. Part II: Ray propagation and comparison with observations, J. Phys. Oceanogr., 33, 802-821.

McCarthy, G. (2011), Variability of thermocline and intermediate waters in the South Atlantic, PhD thesis, 165 pp., Ocean and Earth Sci., Univ. of Southampton, Southampton, U. K.

McCarthy, G., E. L. McDonagh, and B. A. King (2011), Decadal variability of thermocline and intermediate waters at $24^{\circ} \mathrm{S}$ in the South Atlantic, J. Phys. Oceanogr., 41(1), 157-165.

McCartney, M. S. (1977), Subantarctic Mode Water, Deep Sea Res. supplement, 24, 103-119.

McDonagh, E. L., H. L. Bryden, B. A. King, R. J. Sanders, S. A. Cunningham, and R. Marsh (2005), Decadal changes in the South Indian Ocean thermocline, J. Clim., 18, 1575-1590.

Naveira-Garabato, A. C., L. Jullion, D. P. Stevens, K. J. Heywood, and B. A. King (2009), Variability of Subantarctic Mode Water and Antarctic Intermediate Water in Drake Passage during the late 20th and early 21st centuries, J. Clim., 13, 3661-3688.

Polito, P. S., and W. T. Liu (2003), Global characterization of Rossby waves at several spectral bands, J. Geophys. Res., 108(C1), 3018, doi:10.1029/2000JC000607.

Santoso, A., and M. England (2004), Antarctic Intermediate Water circulation and variability using a coupled climate model, J. Phys. Oceanogr., $34,2160-2179$.

Schmidtko, S., and G. C. Johnson (2012), Multi-decadal warming and shoaling of Antarctic Intermediate Water, J. Clim., 25, 207-221.

Stramma, L., and M. England (1999), On the water masses and mean circulation of the South Atlantic Ocean, J. Geophys. Res., 104(C9), 20,863-20,883.

Talley, L. D. (1996), Antarctic Intermediate Water in the South Atlantic, in The South Atlantic: Present and Past Circulation, pp. 219-238, Springer, Berlin.

Wong, A. P. S., N. L. Bindoff, and J. A. Church (1999), Large-scale freshening of intermediate waters in the Pacific and Indian Oceans, Nature, $400,440-443$. 